\title{
AN ANALYSIS OF STRATEGIC PERFORMANCE MEASURES OF COMPANIES listed on the JSE Securities Exchange South Africa
}

\author{
JHvH de Wet and JH Hall
}

Financial Management department, University of Pretoria

\begin{abstract}
This study highlights the importance of economic profits (EVA) and their long-term effects on shareholder value (MVA). South African companies listed on the JSE were analysed and it is evident that the relative measure of internal performance (spreads) can be used to rank companies in terms of value creation. Individual companies and sectors were also placed on a financial strategy matrix, which evaluated companies according to spreads and cash management. The sales growth less the SGR percentage was used to indicate cash management. Statistical tests (regression analysis) were done on the data to test the validity of the financial strategy matrix model. The results showed that there is a positive relationship between spreads and shareholder value, but sales growth less the sustainable growth rate does not contribute significantly to shareholder value.
\end{abstract}

JEL M14

\section{1}

\section{Introduction}

Financial managers generally agree that two of the most important performance measures for a business enterprise are value creation and cash flows. From an investor's point of view, value creation is measured by increases in the share price. It is argued that companies can achieve the greatest impact on shareholder value by maximising internal value creation, which is basically determined by the (operating) returns on their assets relative to their cost of capital.

The objective of this study was to place companies listed on the Johannesburg Securities Exchange South Africa (JSE) on a financial strategy matrix, based firstly on their ability to generate value as expressed by a measure called Economic Value Added (EVA), and secondly to manage sales growth (and its effect on cash/overdraft balances). The "spread" is the difference between the actual return on invested capital and the cost of capital, and value is created when the actual return on assets is higher than the cost of capital. The spread was used, along with the difference between the actual sales growth of a company and its sustainable growth rate (SGR), as a measure of cash management.

A second objective of the study was to place locally listed companies and the sectors in which they operate, on a financial strategy matrix for a given year, or over a period of time. It was anticipated that movements over time (trends) would be helpful in determining the strategies most appropriate for a given company. A next objective was to test the validity or strength of the financial strategy matrix by means of statistical tests that evaluate what impact valuecreating actions have on different measures of shareholder value, such as Market Value Added (MVA).

\section{2}

\section{EVA, MVA and sustainable growth}

A company's total market value is equal to the sum of the market value of its equity and the market value of its debt. In theory, this amount is what can be "taken out" of the company at any given time. The MVA is the difference between the total market value of the company 
and the economic capital (Firer, 1995: 57, Reilly \& Brown, 2003: 591). The economic capital, also called Invested Capital (IC), is the amount that is "put into" the company and is basically the fixed assets plus the net working capital.

MVA = Market value of company - IC

From an investor's point of view, MVA is the best external measure of a company's performance. Stewart (1991: 153) states that MVA is a cumulative measure of corporate performance and that it represents the stock market's assessment from a particular time onwards of the NPV of all a company's past and projected capital projects. The MVA is calculated at a given moment, but in order to assess performance over time, the difference or change in MVA from one date to the next can be determined to see whether value has been created or destroyed.

The concept of EVA is a measure of economic profit and was popularised and originally trademarked by Stern Stewart Consulting Company in the 1980s. EVA is the internal measure of performance that determines MVA. Stewart (1991: 153) defines EVA as follows: "A company's EVA is the fuel that fires up its MVA." EVA takes into account the full cost of capital, including the cost of equity.

The calculation of EVA is very similar to that of the well-known "residual income" measure used as a benchmark of divisional performance for some time. Horngren, Datar and Foster (2003: 790) and Garrison, Noreen and Seal (2003: 616) compare EVA to residual income and other performance measures and describe the growing popularity of EVA.

EVA is calculated as follows:

$$
\mathrm{EVA}=(\mathrm{ROIC}-\mathrm{WACC}) \times \mathrm{IC}
$$

where

ROIC = Return on invested capital;

WACC $=$ Weighted Average Cost of Capital; and

IC = Invested Capital (at the beginning of the year).

The ROIC less the WACC is also called the "return spread". If the return spread is positive, it means the company is generating surplus returns above its cost of capital and this translates into a higher EVA, and ultimately also a higher MVA. Lehn and Makhija (1996: 34) describe EVA as follows: "EVA and related measures attempt to improve on traditional accounting measures of performance by measuring the economic profits an enterprise after-tax operating profits less the cost of the capital employed to produce those profits."

Apart from a company's ability to generate value, the other vital aspect that greatly contributes to its financial success or failure is cash flow management. Hawawini and Viallet (1999: 506) measure the cash management ability of a company by using a differential in percentages that is determined by subtracting the sustainable growth rate (SGR) from the actual growth rate in sales. Growing sales at a rate faster than the SGR (i.e. a positive differential) could cause cash shortfalls and sales growth at a lower rate than the SGR (i.e. a negative differential) could lead to cash surpluses.

Hawawini and Viallet (1999: 506) define the sustainable growth rate of a company as follows: "The self-sustainable growth rate is the maximum rate of growth in sales a business can achieve without changing its financing policy (same debt-to-equity ratio, same dividend payout ratio, and no new issue of equity or share repurchase) or modifying its operating policy (same operating profit margin and same capital turnover)."

In Section 4 it is illustrated how the spread (as internal, relative measure of value creation) and the differential between the sales growth percentage and the SGR (as measure of cash management) of a company are placed on a financial strategy matrix.

\section{3}

\section{Previous research}

Several researchers have published results indicating the relationship between MVA and different internal financial performance measures, including EVA. Stewart (1991: 215) used a sample of 613 companies selected from 
the Stern Stewart 1000 companies. They found that the coefficient of determination $\left(\mathrm{r}^{2}\right)$ for the relationship between average values of MVA and EVA was a very high 97 per cent.

Stern (1993: 36) also performed tests based on average values for MVA, EVA and other accounting performance measures and reported the following results of $\mathrm{r}^{2}$ relative to MVA: EVA 50 per cent; return on equity (ROE) 25 per cent; cash flow growth 22 per cent; earnings per share (EPS) growth 18 per cent; asset growth 18 per cent; dividend growth 16 per cent and turnover growth 9 per cent.

O’Byrne (1996: 119) used nine years of data (for the period 1985 to 1993) for companies in the 1993 Stern Stewart Performance 1000 to test the exploratory power of capitalised EVA (which is EVA divided by the cost of capital), net operating profit after tax (NOPAT), and free cash flows (FCFs) relative to market value divided by IC. Initial findings showed that FCF explained 0 per cent of the change in the market value divided by the capital ratio, while the $\mathrm{r}^{2}$ was 33 per cent for NOPAT and 31 per cent for EVA. It seems therefore as if NOPAT and EVA had almost the same explanatory power.

Milunovich and Tsuei (1996: 111) investigated the correlation between frequently used financial measures (including EVA) and the MVA of companies in the USA computer technology industry (so-called "servervendors") for the period 1990 to 1995 . The $\mathrm{r}^{2}$ of the various performance measures tested relative to MVA were as follows: EVA 42 per cent; EPS growth 34 per cent; ROE 29 per cent; free cash growth 25 per cent, free cash flow 18 per cent. Clearly EVA demonstrated the best correlation in this study and it would be fair to infer that a company that can consistently improve its EVA should be able to boost its MVA and therefore shareholder value.

Hall (1998: 198) investigated the relationship between MVA and EVA, as well as other financial ratios such as ROA, ROE and EPS for companies in South Africa. The study was performed on the top 200 companies listed on the JSE in the period 1987 to 1996 . The sample included only industrial sector companies (financial, investment and mining sector companies were excluded). Hall's (1998: 198) study found relatively low correlation coefficients on the whole. The highest correlation was that between MVA and discounted EVA, with inflation adjustments to the data.

De Wet (2004: 250) used a sample of listed South African companies for the period 1993 to 2002 and tested the relationship between the median values of MVA and EVA, as well as the main drivers of EVA. The $r^{2}$ of the different independent variables tested relative to MVA were as follows: EVA 59 per cent; EBIT/Sales 10 per cent; Sales/IC 9 per cent; Tax rate 22 per cent; WACC 14 per cent; Sales growth 3 per cent and IC 35 per cent.

In spite of the initial strong support of EVA having the strongest impact on MVA, some studies like that of Kramer and Pushner (1997: 41) and Biddle, Bowen and Wallace (1999: 69) have shown that EVA in fact does not have the best explanatory power regarding MVA. The current overall picture, taking into account all the findings to date, is that the debate on the superiority of EVA is inconclusive and will no doubt continue in the foreseeable future.

\section{4}

\section{The financial strategy matrix}

In this section, the concepts of value creation and growth management are combined in a "financial strategy matrix" which links an organisation's ability to create value with its management of growth and cash. Hawawini and Viallet (1999: 507) introduced the financial strategy matrix concept. It represents a diagnostic tool that can be used to evaluate and navigate through the financial progress of a company.

The financial strategy matrix maps the current situation of a company or industry in terms of value creation and growth management by ranking and placing it in a certain quadrant on the matrix. Once this has been done, the matrix can be used to determine appropriate strategies to improve the situation of the company and to move it to a preferred quadrant and, ultimately, to the quadrant it would most like to occupy. 
The return spread, a percentage differential, is the difference between the return on invested capital (ROIC) and the weighted average cost of capital (WACC) and is used as the measure of value creation. A positive return spread indicates value creation, while a negative return spread indicates value destruction. The sustainable growth rate (SGR) of a company is defined as the maximum theoretical rate at which a company can grow on a sustainable basis without having to raise additional longterm finance, like borrowings or share capital.

Growth and cash management are measured by taking the difference between the SGR and the actual growth rate in sales. If this difference is positive (SGR > actual growth rate in sales), it indicates that there is a cumulative cash surplus. A negative difference (SGR $<$ actual growth rate in sales) means that the company is accumulating cash deficits.

The financial strategy matrix indicates value creation (positive or negative) on the vertical axis. The measure used is the return spread (the ROIC less the WACC). Value creation occurs when ROIC > WACC and is indicated on the top (positive) part of the $y$-axis. Value destruction occurs when ROIC $<$ WACC and is indicated on the bottom (negative) part of the y-axis.

The pace at which a company grows, which may result in cash surpluses or cash deficits, is indicated on the horizontal axis of the financial strategy matrix. If the company grows too rapidly, its actual growth rate in sales is more than the SGR and the company will run up cash deficits. This situation would be reflected by a position to the right on the horizontal axis. If, on the other hand, the company's sales and assets are growing at a slower pace than the SGR, there is a build-up of cash surpluses and this situation is indicated by a position to the left on the horizontal axis. The financial strategy matrix is set out in Figure 1 below.

Figure 1

Financial strategy matrix

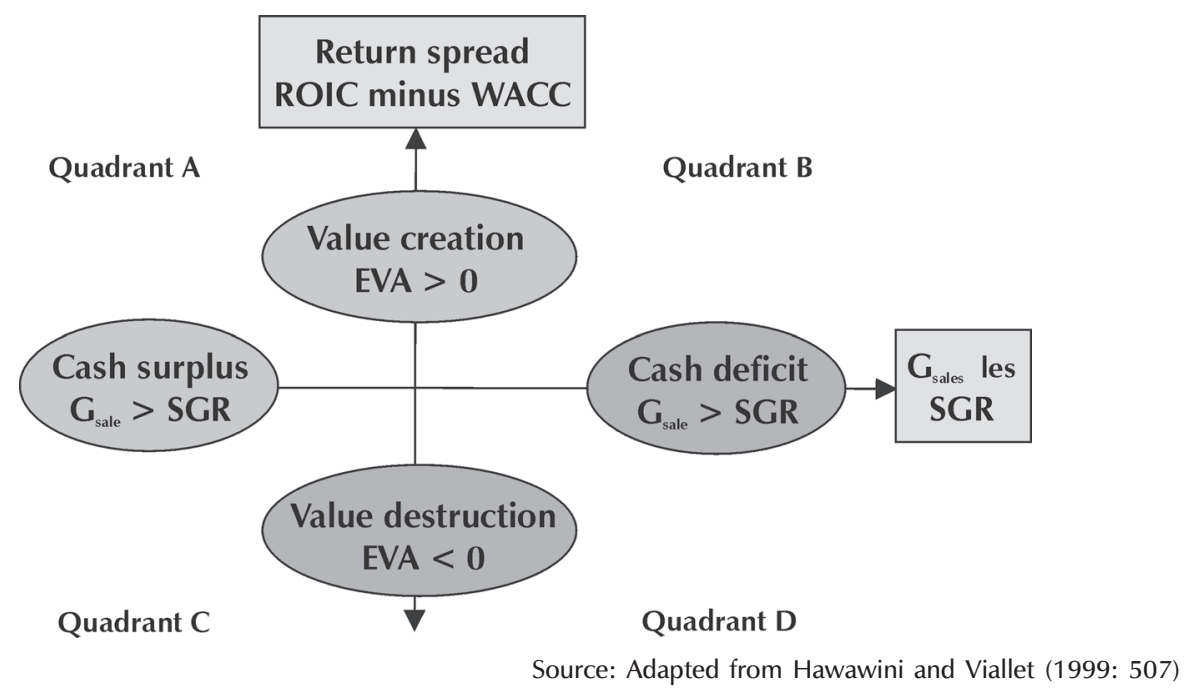

Quadrant A represents the best possible position to be in. Companies in this quadrant are adding value, as is reflected by their positive EVA, and they are not growing too quickly. They do not run up cash deficits. It is fairly obvious that these companies should strive to increase their EVA even more and should also try to make use of the cash surpluses building up each year.

Quadrant B companies do create value (as indicated by a positive EVA), but are growing too fast, thus running up cash deficits. There are two options for a company in this situation. 
The first is to reduce or eliminate dividend payments, if the company is paying a dividend. The second option is to inject new capital into the business by borrowing, or by issuing shares.

Companies in quadrant $\mathrm{C}$ are destroying value, but are also generating cash surpluses. Hawawini and Viallet (1999: 508) suggest that these companies should alter their financial policies quickly, before the cash surplus runs out. They advise that part of the excess cash be returned to shareholders and that the rest of the cash be used to restructure the company in such a way that the returns on IC are increased to a level above the cost of capital.

A quadrant $\mathrm{D}$ company destroys value and runs up cash deficits. This is the worst situation to be in and it requires immediate attention and fast action by management. Drastic restructuring is probably required. Some of the assets of the business must be sold in order to raise cash immediately. Furthermore, the other operations have to be scaled down to change them into value-creating activities.

Monitoring the current situation and progress of a company by mapping its position on a financial strategy matrix helps managers ensure that they allocate scarce funds wisely. Furthermore, it ensures that growth and cash generation are managed well and that the strategic options open to the company in the quest to maximise value for the shareholders are constantly evaluated and considered.

\section{5 \\ Research method}

The preceding sections have provided the theoretical foundation and background to which the empirical study can now be added. This section describes how the data for the empirical study were selected and how the most important variables were calculated and analysed.

The source of the information used in the study was the McGregor's BFA at the University of Pretoria. As a first step, it was decided to use all the companies listed on the JSE in 2002, a total of 419.

Next, it was decided that for the purposes of this study, only industrial companies would provide the required information to determine the critical variables for the analysis. Companies in the mining and financial services sectors, for instance, were not included because their financial statements do not report all the information required for the calculation of these variables. There were 266 industrial companies listed.

The next criterion was the availability of data. Merged companies and those companies that had name changes were automatically excluded on the grounds that there had to be complete data for a specific company for the period 1993 to 2002. In order to have complete, calculated data for the ten-year period from 1993 to 2002, the raw data on each company had to be available for the full twelve-year period from 1991 to 2002 for each company. After eliminating companies with incomplete data, 110 remained.

The final requirement for inclusion in the database was that the data had to be reliable. This aspect was pertinent to this study because the beta factor used in the determination of the cost of equity and the WACC cannot be determined reliably for companies with thinly traded shares. For this reason, all companies with thinly traded shares were eliminated from the database. Companies for which the ordinary share trading volume was below 500000 shares per year for any of the twelve years from 1991 to 2002, were excluded. The number of companies that remained in the final database was 89 .

In order to place a company on the financial strategy matrix, the data for the following variables was required:

ROIC; WACC; Spread (ROIC - WACC); EVA; Sales growth; SGR; and Sales growth less the SGR.

The ROIC was calculated by dividing the net operating profit after tax (NOPAT) by the IC at the beginning of the year and expressing it as a percentage. The WACC was determined by using appropriate weights for each component of long-term capital. A risk-free rate, the market premium and a beta-factor were used in the capital asset pricing model (CAPM) to calculate the cost of equity. The government bond R150 was used as a proxy for the risk-free rate and an 
estimated 6 per cent was used as the market premium, based on guidelines by Brigham and Daves (2004: 58) and Firer, Ross, Westerfield and Jordan (2004: 469). The beta-factor was automatically calculated by the BFA database system. For the other components of long-term capital, such as long-term loans, the appropriate after-tax cost (as adjusted annually per company) was used.

The spread, also called the "return spread", was determined by subtracting the WACC from the ROIC. The EVA was calculated by multiplying the spread with the IC. The EVA was determined for a given year and was expressed as an amount in rand.

Companies provide an estimate of year-onyear sales growth in their annual financial statements and this percentage was used in the analysis. The SGR for a given year (also expressed as a percentage) was determined by dividing the retained income from the previous year by the equity at the beginning of that (previous) year.

\section{6}

\section{Empirical analysis: placement of companies and sectors in the financial strategy matrix}

In this section of the study, companies and sectors were placed in the financial strategy matrix where the growth in sales less the SGR is represented on the $\mathrm{x}$-axis and the spread (ROIC - WACC) on the y-axis. Different companies were selected and placed on the financial strategy matrix for each year from 1993 to 2002. For the purposes of illustration, the results of a very good performer (Pick 'n
Pay), a poor performer (Conafex) and an average performer (Ellerine) are presented in Figure 2, Figure 3 and Figure 4 respectively.

The quadrants of the financial strategy matrix are indicated on each graph. Quadrant A indicates a positive spread and negative sales growth less the SGR percentage, while quadrant B shows a positive spread and a positive sales growth less the SGR percentage. Quadrant C indicated a negative spread and a negative sales growth less the SGR percentage, while quadrant $\mathrm{D}$ is used for a negative spread and a positive sales growth less the SGR percentage.

Figure 2 shows that Pick ' $n$ Pay consistently had positive spreads for the whole period under review, viz. from 1993 to 2002. Its excellent performance is emphasised by the fact that its spread was more than 20 per cent each year for the last seven years from 1996 to 2002. As far as its sales growth is concerned, the graph shows that the sales growth less the SGR was negative for four years and positive for six years. It is also not possible to find a trend that indicates that the growth in sales is managed in such a way that it remains below the SGR percentage.

Looking at the results of Conafex, it is clear that there were negative spreads for each of the ten years from 1993 to 2002. It seems as if the trend in terms of spreads got worse over time. Not surprisingly, the results for five years fell in the D quadrant, where the only options left to the company are to restructure radically or to close down.

The results of the company Ellerine in Figure 4 indicate low to average spreads, but the spread was negative for only one year (1999). The differential between sales growth and the SGR remained negative for the whole ten-year period. Consequently, the results fall in the A quadrant for nine out of the ten years. 
Figure 2

Pick 'n Pay - each year from 1993 to 2002

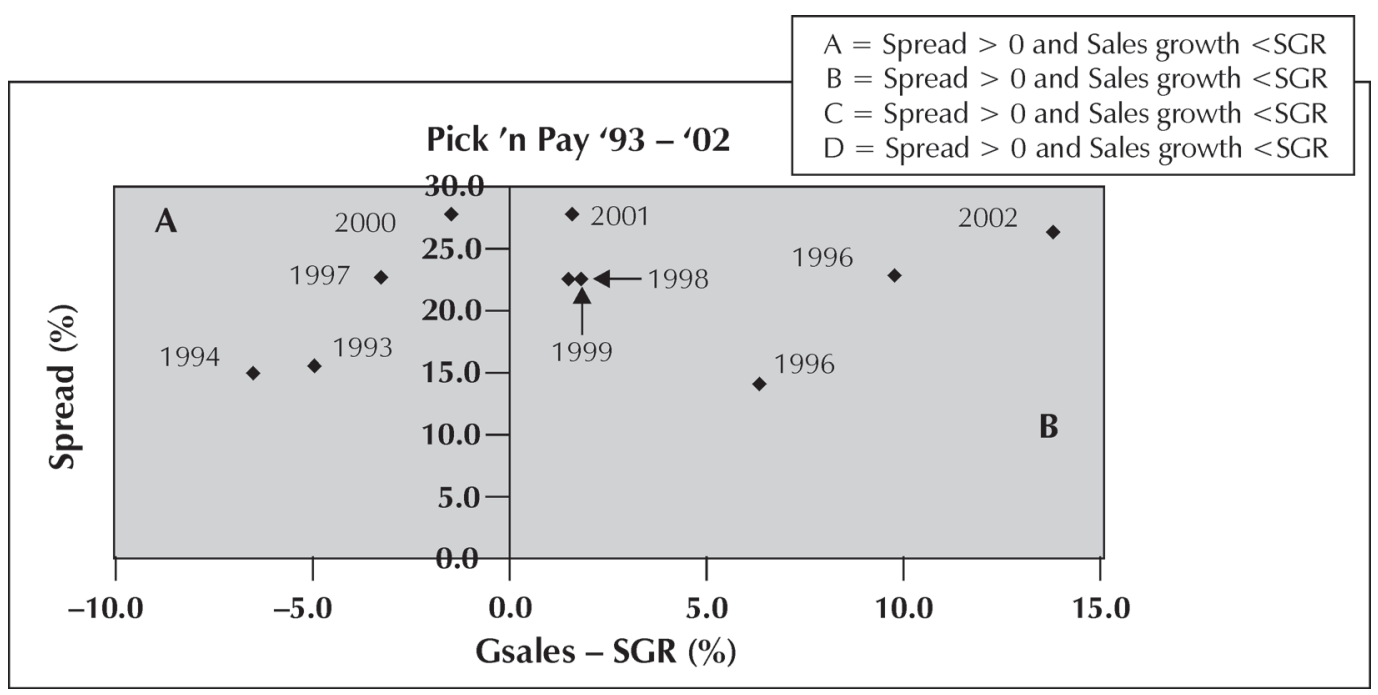

Figure 3

Conafex - each year from 1993 to 2002

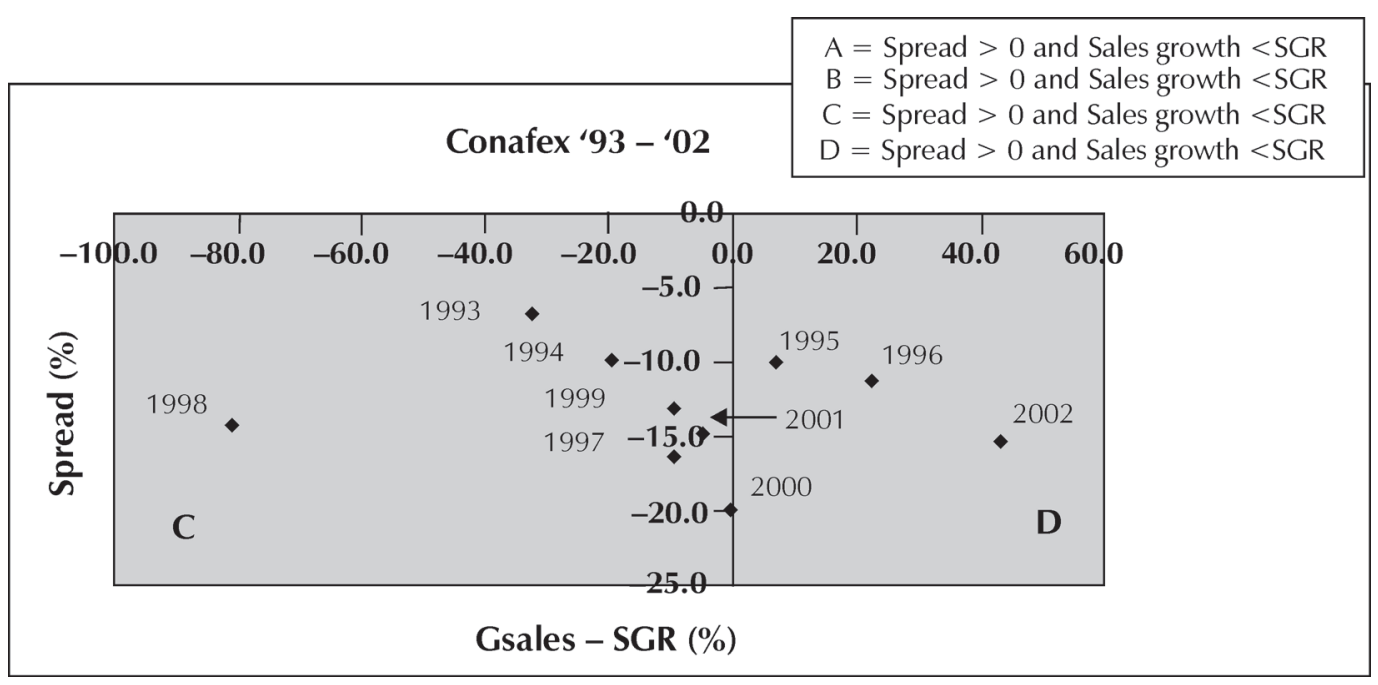




\section{Figure 4}

Ellerine - each year from 1993 to 2002

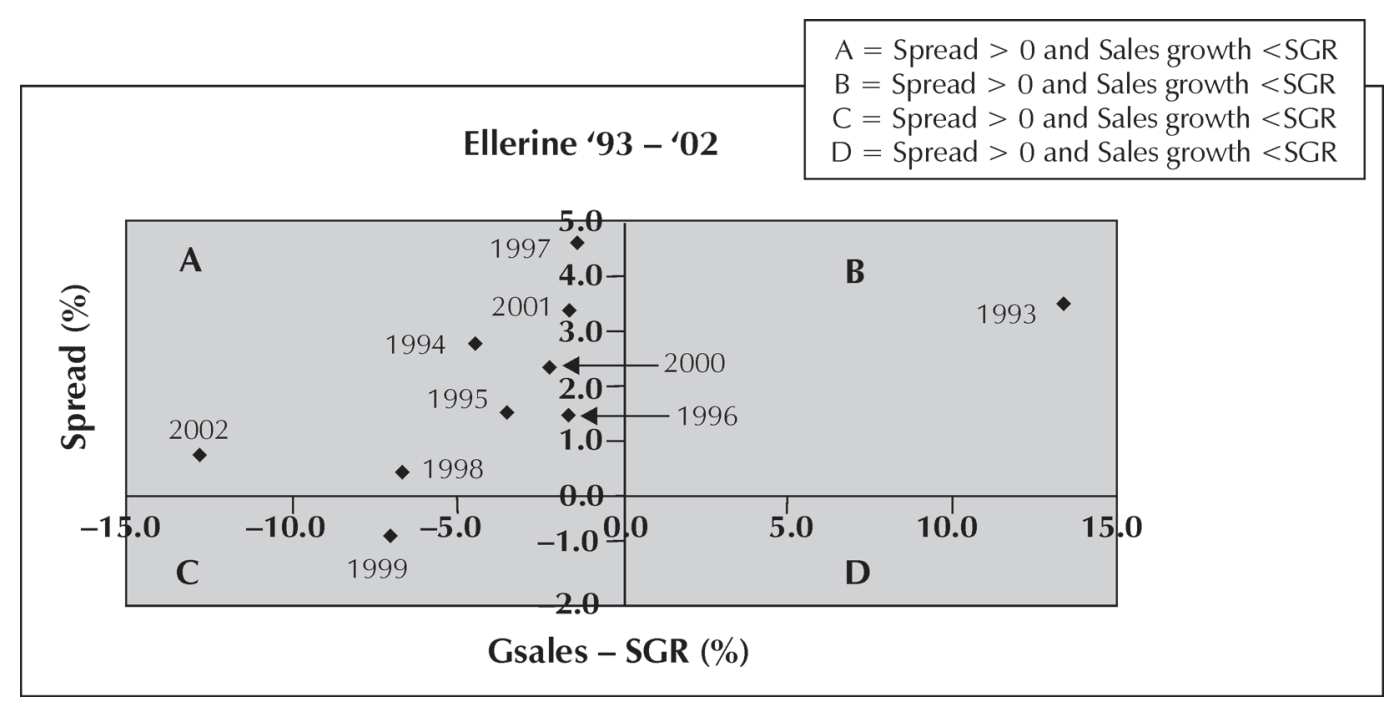

After analysing the results of individual companies, the study proceeds by placing the results of the different sub-sectors represented by the companies selected, as well as the results of all the companies, on the financial strategy matrix.

The medians for the ten-year period from 1993 to 2002 for each sub-sector are set out in Figure 5. The food and drug retailers sector (Sub-sector 21), with a median spread of 21.2 per cent (next best 8.3 per cent) stands out as the best-performing sector by far. Of the 23 subsectors, 14 had positive spreads, while 10 subsectors were classified in the B quadrant. Four sub-sectors were placed in the A quadrant and eight in the D quadrant.

As another way to compare the results from year to year, the median results of all companies for each year from 1993 to 2002 are shown in Figure 6. It shows that the median spread for all companies was positive each year from 1993 to 2002 (with a lowest spread of 0.4 per cent in 1996 and a highest spread of 6.5 per cent in 2002). In terms of spreads, there was a clear upward trend from 1999 (1.4 per cent) to 2002 (6.5 per cent). The median sales growth less the SGR percentage was negative for only three years (1993, 1997 and 1999). For the other years, the median sales growth less the SGR percentage was positive, indicating a possible build-up of cash shortages.

The placement of companies, sub-sectors and all company medians on the financial strategy matrix revealed that a company could very seldom be categorised in only one quadrant for each of the ten years from 1993 to 2002. This is mostly due to the varying nature of the sales growth less the SGR percentage, which could be positive in one year and negative in the next.

The placement of the results per sector and the comparison between sectors show that the food and drug-retailing sector had dramatically higher median spreads than the other sectors for the whole period from 1993 to 2002. The median spread of the food and drug-retailing sector was above 20 per cent for 1993 to 2002, while the second-best sectors had a median spread of below 10 per cent. For the period 1993 to 2002, the majority of sectors had positive median sales growth less SGR percentages (18 out of 23 sectors).

The placement of all companies in the matrix highlighted some notable issues. The first is that the majority of companies had positive rather than negative spreads each year from 1993 to 2002. There is an increasing trend over time in 
terms of spreads. The median sales growth less the SGR percentage for all companies was positive for seven years and negative for three years. This indicates that cumulative cash shortages may be a problem. However, this percentage may be an unreliable measure of cash generation/shortfalls because the SGR does not take sales growth into account because of new investment in assets financed with new issues of debt or equity.

In the next section the statistical tests performed to test the strength of the financial strategy matrix model are addressed.

Figure 5

Medians per sub-sector 1993 to 2002

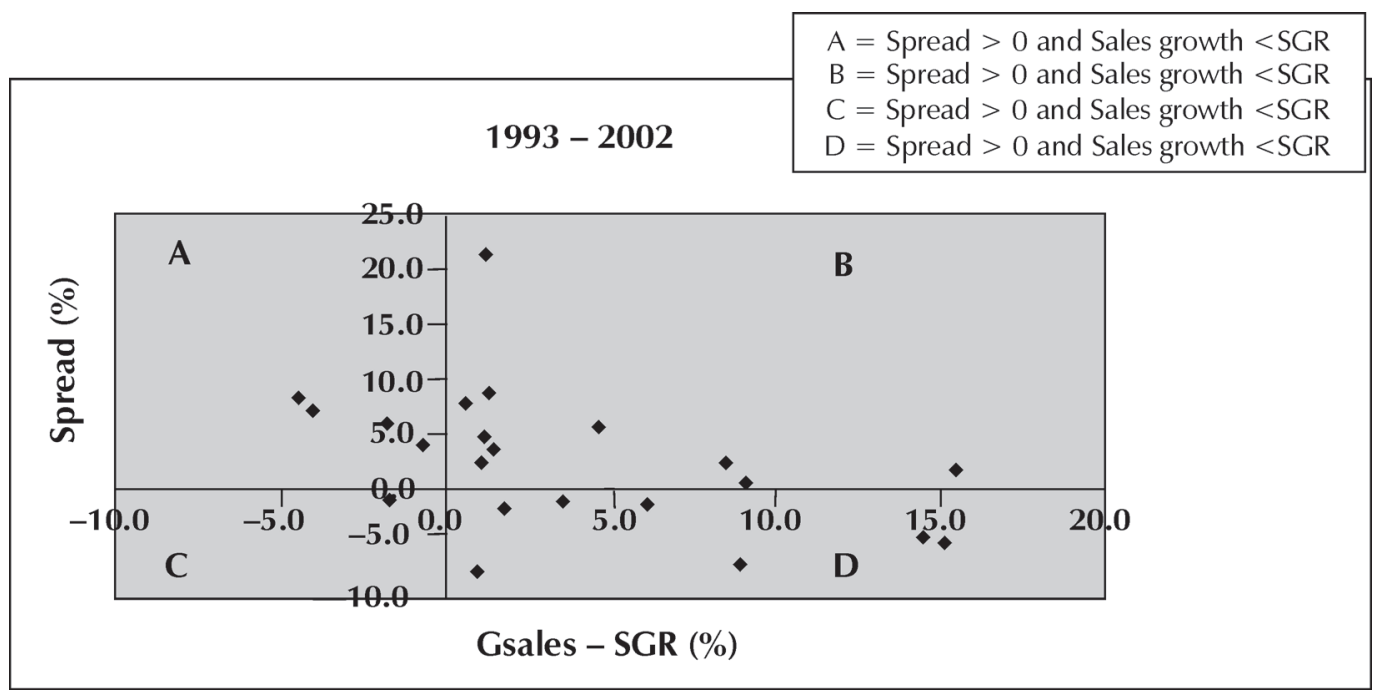

Figure 6

Medians all companies each year from 1993 to 2002

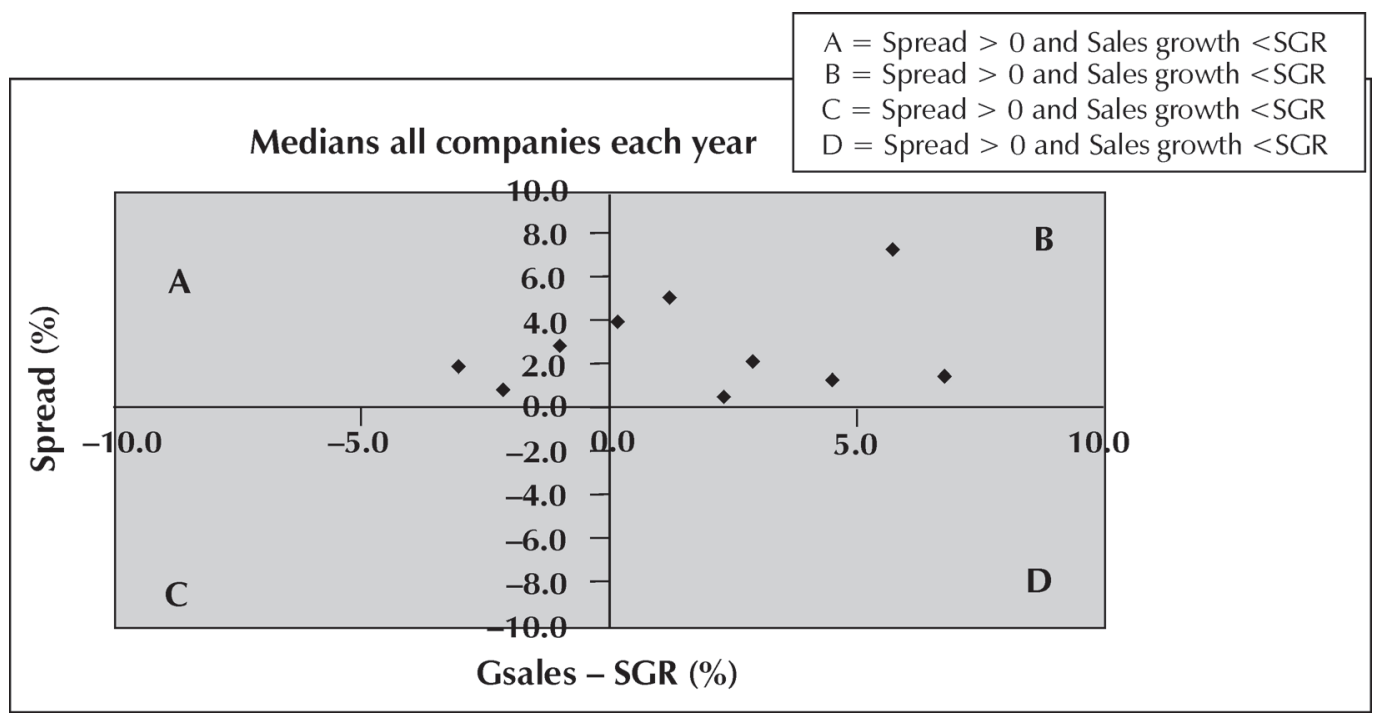




\section{7}

\section{Statistical tests of the validity of the financial matrix model}

In the preceding section it was demonstrated that specific companies, sectors and all companies as a group were placed on the financial strategy matrix in order to determine trends over time. This section discusses the results of statistical tests and regressions used to test what impact the two performance measures used for the financial strategy matrix (spreads and sales growth less the SGR percentage) have on shareholder value.

Linear regression analysis was used to determine the impact of the main components (drivers) of EVA on MVA and changes in MVA. If this analysis can identify the specific determinants that have the biggest impact on MVA, it will enable financial managers to narrow down their focus to those drivers that will unlock and increase the most value for shareholders and improve their company's position on the financial strategy matrix.

From the outset it must be borne in mind that MVA and changes in MVA are external measures that are affected by external factors (to a very large extent) and also by internal factors, for instance EVA and sales growth. Shareholders' expectations affect MVA and changes in MVA dramatically and therefore changes in the environment, such as political instability, can have a vast effect on these measures. Consequently, it can be expected that the impact of internal factors might not carry very much weight, especially in the short term.

\subsection{The impact of spreads and sales growth less the SGR percentage on MVA and changes in MVA}

The goal of this statistical test was to assess the impact of spreads and the differential of sales growth less the SGR percentage on MVA. Bearing in mind that both spreads and sales growth less the SGR percentage are single-year, relative measures of performance compared to MVA, which is a cumulative, absolute measure of performance, it was decided to replace MVA with a related, relative measure of performance for the purposes of the regression analysis.

The first proxy measure used in place of MVA was the "growth differential", which is discussed in Section 7.1.1. The correlations of other proxies for MVA were also tested relative to spreads and sales growth less the SGR percentage. In Section 7.1.2, the regression results are shown when the change in MVA (over the last year) is used in place of MVA.

\subsubsection{Regression of spreads and sales growth less the SGR percentage relative to the "growth differentials"}

The measure chosen to replace MVA is the difference between the "implied expected growth in EVA" and the historical growth in EVA. The "implied expected growth in EVA" is based on the market's expectation (as reflected by the independently determined MVA) of the current EVA and the future growth in the EVA of a company. This approach is analogous to the price-implied expectations (PIE) approach used by Rappaport and Mauboussin (2001: 70).

In a nutshell, the PIE approach of Rappaport and Mauboussin (2001: 70) entails using the information content of the market value of a share in conjunction with free cash flow projections to estimate the implied number of years it will take for the present value of the expected future cash flows to be equal to the market value of the company. The resulting number of years is then considered to determine whether the current share price represents reasonable value or not.

When the historical growth rate in EVA is deduced from this "implied expected future growth rate", the difference is expected to be smaller for companies that are considered good performers (and bigger for those that are considered not to be good performers). A survey of the data for the listed companies included in the final database indicates that for the majority of these companies, the historical growth rate in EVA over the last number of years (1993 to 2002) was, with very few exceptions, consistently higher than the "implied expected growth rate".

Intuitively, this makes sense because the market, as reflected by the MVA, is unlikely to 
expect EVA to keep on growing at the same rate as the most recent historical growth rate, and it is also unrealistic to expect this EVA growth to continue indefinitely in future. Therefore, if a linear regression is done between this "growth differential" and spreads, it is to be expected that there will be a negative correlation for companies performing well and a smaller, negative correlation for companies that are not performing well.
Furthermore, only companies that had positive spreads (and EVAs) for a sufficient number of years (a minimum of five years) so that a credible historical growth rate in EVA could be calculated, were included in the group of companies for this regression analysis. After eliminating some companies according to these criteria, only 30 companies remained (out of the initial 89). The names of the 30 companies, as well as the relevant information for each one, are set out in Table 1.

\section{Table 1}

Spreads and sales growth less the SGR percentages relative to "growth differentials"

\begin{tabular}{|c|c|c|c|c|c|c|c|c|}
\hline & & & & & & A & B & $A-B$ \\
\hline & & & & & & Historical & $\begin{array}{c}\text { Implied } \\
\text { expected } \\
\text { future }\end{array}$ & \\
\hline & & & & $\mathbf{G}_{\text {sales }}$ & $\begin{array}{c}5 \mathrm{yr} \\
\text { median }\end{array}$ & $\begin{array}{c}\text { EVA } \\
\text { growth }\end{array}$ & & \\
\hline No & Company & Year & Spread & -SGR & $\mathbf{G}_{\text {sales }}-\mathbf{S G R}$ & & EVA growth & Difference \\
\hline & & & $\%$ & $\%$ & $\%$ & $\%$ & $\%$ & $\%$ \\
\hline 1 & SHOPRITE & 2002 & 38.7 & 4.9 & 0.3 & 30.1 & -1.1 & 31.2 \\
\hline 2 & MNET-SS & 2002 & 28.5 & 29.8 & 46.8 & 29.8 & -2.1 & 32.0 \\
\hline 3 & ALTECH & 2002 & 27.2 & -21.5 & -3.0 & 56.5 & -2.6 & 59.0 \\
\hline 4 & PICKNPAY & 2002 & 24.8 & 13.3 & 1.4 & 17.8 & 4.0 & 13.8 \\
\hline 5 & BOWCALF & 2002 & 22.7 & 0.5 & 0.5 & 31.3 & -9.1 & 40.4 \\
\hline 6 & СМH & 2002 & 21.9 & -9.9 & -6.0 & 35.5 & -24.4 & 59.9 \\
\hline 7 & DELTA & 2002 & 20.7 & 6.5 & -4.9 & 35.9 & 1.8 & 34.1 \\
\hline 8 & OCEANA & 2002 & 20.6 & 0.7 & 0.7 & 23.1 & 0.0 & 23.1 \\
\hline 9 & CERAMIC & 2002 & 20.5 & 0.1 & 3.5 & 24.5 & 5.1 & 19.4 \\
\hline 10 & ITLTILE & 2002 & 19.8 & 8.9 & -2.1 & 60.5 & 3.0 & 57.5 \\
\hline 11 & TIGBRANDS & 2002 & 16.6 & -28.5 & -15.9 & 18.7 & 0.2 & 18.6 \\
\hline 12 & BEARMAN & 2002 & 16.4 & -10.3 & 6.4 & 25.0 & -22.9 & 47.8 \\
\hline 13 & UNITRAN & 2002 & 15.1 & 1.5 & 5.0 & 34.3 & -47.9 & 82.2 \\
\hline 14 & CHEMSVE & 2002 & 14.4 & 9.5 & -15.8 & 42.6 & -1.0 & 43.6 \\
\hline 15 & METCASH & 2002 & 11.4 & 86.9 & 86.9 & 31.1 & 1.1 & 30.0 \\
\hline 16 & AHEALTH & 2002 & 11.3 & 13.9 & 14.5 & 53.0 & -5.3 & 58.3 \\
\hline 17 & WBHO & 2002 & 11.3 & 8.5 & -2.4 & 27.2 & -90.7 & 118.0 \\
\hline 18 & BIDVEST & 2002 & 11.1 & 14.7 & 14.7 & 55.8 & 7.7 & 48.1 \\
\hline 19 & REUNERT & 2002 & 10.3 & 9.3 & -0.4 & 4.9 & 8.2 & -3.3 \\
\hline 20 & SASOL & 2002 & 10 & 20.3 & 20.3 & 104.0 & -6.1 & 110.1 \\
\hline
\end{tabular}




\begin{tabular}{|r|l|r|r|r|r|r|r|r|}
\hline 21 & NUCLICKS & 2002 & 9.9 & 6.0 & 6.0 & 30.1 & -0.1 & 30.2 \\
\hline 22 & MEDCLIN & 2002 & 9.7 & 3.2 & 3.2 & 42.5 & -7.7 & 50.2 \\
\hline 23 & MRPRICE & 2002 & 8.8 & 0.8 & 0.8 & 38.7 & -34.9 & 73.6 \\
\hline 24 & HUDACO & 2002 & 8 & 22.4 & -10.5 & 5.1 & -8.3 & 13.4 \\
\hline 25 & PPC & 2002 & 8 & 27.5 & -1.0 & 21.6 & -1.1 & 22.7 \\
\hline 26 & ABI & 2002 & 7.7 & -5.9 & -5.9 & 22.0 & 8.8 & 13.1 \\
\hline 27 & AFROX & 2002 & 6.8 & 9.3 & 9.3 & 23.7 & 2.6 & 21.1 \\
\hline 28 & IMPERIAL & 2002 & 3.4 & 16.1 & 16.1 & 42.4 & -4.5 & 46.9 \\
\hline 29 & NAMPAK & 2002 & 2.5 & 26.7 & -3.1 & -1.1 & 4.6 & -5.7 \\
\hline 30 & CAXTON & 2002 & 1.1 & -3.0 & -6.8 & -0.9 & -1.6 & 0.7 \\
\hline
\end{tabular}

For the purpose of the regression analysis, the 30 companies were divided into two groups of 15 each, namely the top 15 and 16 to 30 . With regard to the regression between the spreads and the growth differential, it was anticipated that the top 15 would show a larger negative correlation than the second group of 16 to 30 . The regression results showed a correlation coefficient of $-0,166$ for the top 15 group. For the 16 to 30 group, there was a positive correlation between the spreads and the growth differential, with a correlation coefficient of $+0,535$. This result was quite different from what was expected (namely a smaller, negative correlation coefficient). Based on these results, one could still assert that higher spreads go with higher value (and lower growth differentials) in the case of the companies with the higher spreads (the top 15). It is hard to explain why there was a positive correlation between spreads and growth differentials for the second group of companies (16 to 30).

As a next step, a regression was done of the sales growth less the SGR percentage and the growth differentials of each company, again using the two groups indicated above. It was expected that there would be little correlation between these two variables, even if the financial matrix model suggests that sales growth above the SGR percentage would cause cash shortages and that this may have a negative impact on the value of a business.

For the top 15 companies the correlation coefficient was -0.189 , which indicates that the higher the sales growth less the SGR percentage, the lower the growth differential (and therefore the higher the value). This result is the opposite of what was implied in the financial strategy matrix model. However, a possible reason for this could be that high sales, in spite of their negative impact on cash flows, also lead to higher spreads and thus contribute to higher value.

For the 16 to 30 group of companies, the correlation coefficient of the same variables was insignificantly small. This is opposed to the underlying theory of the financial strategy model, but it does strengthen the hypothesis that the difference between sales growth and the SGR percentage for a given year does not play a large part in determining the value of a company.

In order to guard against dismissing the impact of controlled sales growth on the value of the business too easily, it was decided to also do a regression analysis between the growth differential and a five-year median for sales growth less the SGR percentage. This would show whether the sales growth relative to the SGR percentage does indeed play a role in value determination, if not for a given year, then perhaps over a period of time.

For the top 15 companies, the correlation coefficient was -0.136 , which is not very different from the result for the regression of sales growth less the SGR percentage for a given year. For the 16 to 30 group of companies, the correlation coefficient was +0.487 . This result 
was surprising, because it indicates that higher sales growth less the SGR percentage goes with higher growth differentials (and lower value). On its own, it supports the financial strategy model, but compared to the same regression for the top 15 group, it does not give a clear signal regarding the impact of sales growth relative to the SGR percentage on the value of a company.

Using the "growth differential" as a measure of value may have some shortcomings which, under certain circumstances, could provide unreliable results. For instance, if the historical growth in EVA starts off strongly and then tapers off or even becomes negative in later years, the "average" historical growth rate in EVA over the whole period will be low. When this is compared to the "implied expected growth rate", the difference may be small. The low "growth differential" may be wrongly interpreted as "high value". This phenomenon may also account for the significant positive correlation between the spreads and the "growth differentials" of the group of companies with the lower spreads (the 16 to 30 group).

\subsubsection{Regression of spreads and sales growth less the $S G R$ percentage relative to changes in MVA}

Finding an appropriate, reliable indicator of value against which the spreads and sales growth less the SGR percentage can be correlated, is not a straightforward exercise. To overcome the limitations of using only one measure of value, two other measures were used as well. A regression was done using the (one-year) "change in MVA" instead of the "growth differential" as a measure of value. This time, all the data for the 89 companies for the nineyear period from 1994 to 2002 were used (1993 was the first year and because only changes were taken into account, the 1993 data were discarded). After the data had been sorted according to spreads, only data pertaining to positive spreads were retained. The 499 data observations with positive spreads were divided into two groups, namely the top 250 and the 251 to 499 groups.

In this instance, one would expect a positive correlation between changes in MVA and spreads and that the correlation would be stronger for the companies with higher spreads. For both the sales growth less the SGR percentage and the five-year median sales growth less the SGR percentage, it was expected that there would be a low correlation and, if anything, that it would be negative (indicating that the higher the sales growth is above the SGR, the weaker the cash control and therefore the lower the value).

The results were the following: the correlation coefficient of the regression between the change in MVA and the spreads was -0.3135 for the top 250. This negative correlation is the opposite of what was expected. For the 249 to 499 group the correlation coefficient was 0.0552 . From this result it is impossible to tell whether spreads influence value positively (the opposite seems to be the case). It is also not possible to infer that the values of companies with higher spreads are influenced more by their spreads than those with lower spreads.

The results of the regression between the changes in MVA and the sales growth less the SGR percentage, as well as that between the changes in MVA and the five-year median sales growth less the SGR percentage, were very low, in fact, almost insignificant correlations. For the top 250, the correlation coefficient (for the change in MVA and sales growth less the SGR percentage) was +0.0391 and for the 251 to 499 it was -0.0008 , indicating very low levels of correlation and little difference between companies with high spreads and those with low spreads. The correlation coefficient for the regression between the changes in MVA and the five-year median sales growth less the SGR percentage was +0.0622 for the top 250 group and -0.0926 for the 251 to 499 group. The results were not very different when the actual sales growth less the SGR percentage for a given year was used as opposed to when the five-year median was used.

The general conclusion drawn from the regressions (done at a 5 per cent significance level) discussed here is that neither spreads nor sales growth less the SGR percentages had a significant impact on the measures used for value on a year-on-year basis. The implication of this is that the usefulness of the financial 
strategy matrix as a financial management tool can be questioned, especially if it is used only for the results of one specific year. Further investigation would be required to ascertain whether there are better causal relationships (between spreads and value, for instance) with more statistical significance if values are determined over a longer period, for instance five or ten years.

\section{8}

\section{Conclusion \& recommendations}

The placement of individual companies on the financial strategy matrix revealed that a company could very seldom be categorised in only one quadrant for each of the ten years from 1993 to 2002. It also showed the consistent good performance of Pick 'n Pay in terms of spread. The placement of the results per sector and the comparison between sectors show that the food and drug-retailing sector had dramatically higher median spreads than the other sectors for the whole period from 1993 to 2002. The placement of all companies in the matrix revealed that the majority of companies had positive rather than negative spreads each year from 1993 to 2002. An increasing trend over time in terms of spreads was also found.

The strategic options available to a company finding itself in a specific quadrant are the following (Hawawini \& Viallet, 1999: 508):

If a company finds itself in Quadrant A:

- Use cash surplus to grow faster

- Make new investments (organic growth).

- Acquire related businesses.

- Distribute the cash surplus

- Increase dividend payments.

- Repurchase shares.

The options for managers of Quadrant B companies can be summarised as follows:

\section{- Cut dividends}

- Raise funds

- Increase new equity.

- Increase borrowing.
- Reduce growth in sales to a sustainable level

- Eliminate low margins and low capital turnover products.

The strategic steps that can be taken by management of a Quadrant C company are the following:

- Distribute part of the cash surplus and use the rest to improve profitability

- Raise the efficiency with which assets are managed.

- Increase the operating margin (higher volume, higher prices and tighter control over expenses).

\section{- Review capital structure policy}

- If the current capital structure is not optimal, modify the debt/equity ratio in order to lower the WACC.

\section{- If the above fails, sell the business}

The only two options available for managers of struggling companies in Quadrant D are the following:

\section{- Attempt drastic restructuring}

\section{- Liquidate the business}

Managers must, after determining the position of their companies on the financial strategy matrix, try to improve their relative position to a better quadrant. The guidelines above will provide them with an indication of the actions that they can undertake depending on the quadrant within which they find their company. The aim of the previous section (Section 7) was to describe the statistical tests used to verify the strength of the financial strategy matrix and to report on the results. The impact of spreads and sales growth less the SGR percentage on two different measures of value were tested. The measures used to represent value were the "growth differentials" and changes in MVA. For these tests, only companies with positive spreads (and EVAs) were used, because no relationships were expected between the spreads (and sales growth less the SGR percentage) and the market value of companies with negative spreads.

As far as the impact of spreads on the two measures of value is concerned, some results 
indicated a positive relationship. However, when the group of companies with high spreads was compared to the group with low spreads, it was not possible to tell whether higher spreads had a bigger impact on value than lower spreads.

The relationship between sales growth less the SGR percentage and the three measures of value proved to be very weak and almost nonexistent. The reason for this may be that high sales growth may give two different signals. The one is that the high sales growth may indicate bad cash management and lead to a build-up of cash shortages (as highlighted by the financial strategy matrix). High sales growth may also be regarded as a driver for higher profits and in that way contribute to higher value. Based on this outcome, one can conclude that the sales growth less the SGR percentage does not have a significant impact on value at all.

The general conclusion from the statistical tests is that the results were not significant and conclusive enough to say that the two criteria plotted on the financial strategy matrix model have a significant effect on shareholder value on a single-year basis.

The study has tested the impact of the two variables evaluated by the model on shareholder value and has suggested some adjustments in order to improve the relevance and efficiency of the model. These suggestions were also aimed at expanding the single-year model to a periodic model that reflects changes over time and facilitates comparisons with sector averages and the average results of all companies. These adjustments will hopefully allow analysts to not only judge the level better, but also the consistency and sustainability of a company's performance.

\section{References}

1 BIDDLE, G.C.; BOWEN, R.M. \& WALLACE, J.S. (1999) "Evidence on EVA", Journal of Applied Corporate Finance, 12(2): 69-79.

2 BRIGHAM, E.F. \& DAVES, P.R. (2004) Intermediate Financial Management. ( $8^{\text {th }}$ ed.) Thomson: Mason, Ohio.
3 DE WET, J.H.vH. (2004) "A strategic approach in managing shareholders' wealth for companies listed on the JSE securities exchange South Africa", Doctoral thesis, University of Pretoria, Pretoria.

4 FIRER, C. (1995) "Investment basics XXX EVA $^{\mathrm{TM}}$ : the real key to creating value", Investment Analysts Journal, 40(Summer)1994/ 95: 57-59.

5 FIRER, C.; ROSS, S.A.; WESTERFIELD, R.W. \& JORDAN, B.D. (2004) Fundamentals of Corporate Finance, ( $3^{\text {rd }}$ SA ed.) McGraw-Hill: New York.

6 GARRISON, R.H.; NOREEN, E.W. \& SEAL, W. (2003) Management Accounting (European ed.) McGraw-Hill: New York.

7 HALL, J.H. (1998) "Variables determining shareholder value of industrial companies listed on the Johannesburg Stock Exchange”, Doctoral thesis, University of Pretoria: Pretoria.

8 HAWAWINI, G. \& VIALLET, C. (1999) Finance for Executives, Thomson: Cincinnati, Ohio.

9 HORNGREN, C.T.; DATAR, S.M. \& FOSTER, G. (2003) Cost Accounting - A Managerial Emphasis, (11 $1^{\text {th }}$ ed.) Prentice-Hall: New York.

10 KRAMER, J.K. \& PUSHNER, G. (1997) "An empirical analysis of economic value added as a proxy for market value added", Financial Practice and Education, Spring/Summer: 41-49.

11 LEHN, K. \& MAKHIJA, A.K. (1996) "EVA and MVA as performance measures and signals for strategic change", Strategy \& Leadership, May/ June: 34-38.

12 MILUNOVICH, S. \& TSUEI, A. (1996) "EVA in the computer industry", Journal of Applied Corporate Finance, 9(1): 104-115.

13 O'BYRNE, S.F. (1996) "EVA and market value", Journal of Applied Corporate Finance, 9(1): 116-125.

14 RAPPAPORT, A. \& MAUBOUSSIN, M.J. (2001) Expectations Investing: Reading Stock Prices for Better Returns, Harvard Business School Press: Boston.

15 REILLY, F.K. \& BROWN, K.C. (2003) Investment Analysis Portfolio Management ( $7^{\text {th }}$ ed.) Thomson-South Western: Cincinnati.

16 STERN, J. (1993) "Value and people management”, Corporate Finance, July: 35-37.

17 STEWART, G.B. III (1991) The Quest for Value, Harper-Collins: New York. 